\title{
Erratum to: The temperature dependence of the work function of oxide electrodes in fluorescent lamps ${ }^{\star}$
}

Eur. Phys. J. Appl. Phys. 92, 11301 (2020). https://doi.org/10.1051/epjap/ 2020190363

Reinhard Langer ${ }^{1,2,{ }^{*}, \mathrm{a}}$ and Reinhard Tidecks ${ }^{1}$

${ }^{1}$ Institut für Physik, Lehrstuhl für Experimentalphysik II, Universität Augsburg, Universitätsstraße 1, 86159 Augsburg, Germany

2 LEDVANCE GmbH (former part of OSRAM AG), Berliner Allee 65, 86136 Augsburg, Germany

Received: 13 October 2021 / Accepted: 13 October 2021

During further work on this topic, we recognized that some corrections and additions have to be made in our above article, which are summarized in Footnote 1 at the end of the text of our recent publication:

R. Langer, I. Paul, R. Tidecks, Impact of damaging and recovery on the temperature dependence of the work function of oxide electrodes in fluorescent lamps, Eur. Phys. J. Appl. Phys. 96, 11301 (2021), https://doi.org/10.1051/epjap2021/ 210149

We apologize for the errors made.

Cite this article as: Reinhard Langer, Reinhard Tidecks, Erratum to: The temperature dependence of the work function of oxide electrodes in fluorescent lamps, Eur. Phys. J. Appl. Phys. 96, 21301 (2021)

\footnotetext{
$\star$ The online version of the original article can be found at https://doi.org/10.1051/epjap/2020190363

* e-mail: reinhard.langer-physik@t-online.de

${ }^{a}$ Present address: Deutsches Patent- und Markenamt, Zweibrückenstraße 12, D-80331 München, Germany. This article represents the author's personal opinion and not that of the German Patent and Trademark Office.
} 